\title{
ANTONIO CANDIDO - UMA CRÍTICA DE VERTENTES
}

Gustavo Arnt ${ }^{1}$

Resumo: O presente artigo apresenta um panorama dos principais conceitos da produção crítica de Antonio Candido, de forma a elucidar algumas questões relativas ao seu método crítico. Partindo do conceito de sistema literário, analisamos a relação dialética que conceitos como empenho, formação, tradição etc. estabelecem entre si, e sugerimos que os próprios conceitos formam um sistema, que chamamos de "sistema conceitual crítico".

Palavras-chave: Antonio Candido, crítica literária, dialética

\section{ANTONIO CANDIDO - A CRITICAL OF WATERSHEDS}

Abstract: This article presents an overview of the key concepts from the critical production of Antonio Candido, in order to clarify some issues regarding their critical method. Based on the concept of literary system, we analyze the relationship dialectic that concepts such as commitment, training, tradition etc. lay between them, and suggest that the very concepts form a system, what we call "critical conceptual system".

Key worlds: Antonio Candido, literary criticism, dialetics

"Arguto, sutil Antonio, a captar nos livros a inteligência e o sentimento das aventuras do espírito, ao mesmo tempo em que, no dia brasileiro, desdenha provar os frutos da árvore da opressão, e, fugindo ao séquito dos poderosos do mundo, acusa a transfiguração do homem em servil objeto do homem."

Carlos Drummond de Andrade (1979)

Ao denominar seu método de trabalho como "crítica de vertentes" (TAVARES, 1999, p. 2-4), Antonio Candido nos mostra que os estudos de obras literárias que se pretendem de fato crítica literária devem sempre levar em conta a natureza do texto e, consequentemente, adaptar o método a ela. Isso significa dizer que o crítico não deve chegar com opiniões pré-definidas em relação ao texto em análise, mas partir dos elementos interpretativos oferecidos pela própria obra. É o que Candido nos ensina também ao afirmar "o meu ponto de partida é sempre empírico. Em crítica literária é sempre a mesma coisa. Nunca leio uma teoria e digo 'Vou aplicar'. Leio um autor e digo: 'como é que eu vou explicar este texto?"” (JACKSON, 2002, p.56). Em outro

\footnotetext{
${ }^{1}$ Doutorando em Teoria Literária e Literatura Brasileira pelo Departamento de Teoria Literária e Literaturas da Universidade de Brasília (TEL/UnB). E-mail: gustavo_arnt@hotmail.com.
} 
momento, Candido refere-se a seu método como "histórico e estético ao mesmo tempo" (CANDIDO, 2006a, p.18), o que é uma das chaves para o entendimento da crítica materialista, pois a estética não é uma abstração idealista e deve ser estudada e compreendida em suas manifestações históricas materiais.

Além disso, ao longo da obra de Candido está presente também uma gama de conceitos que se ligam dialeticamente à metodologia, ou seja, os conceitos são gerados por meio da prática crítica ao mesmo tempo em que fazem com que essa prática se transforme e ganhe forma ao longo do desenvolvimento conceitual estabelecido em cada ensaio.

Sendo assim, nos propomos neste estudo a traçar um panorama dos conceitos da crítica de Antonio Candido, tendo em vista uma melhor compreensão do seu método crítico. Nesse ponto, é interessante assinalar que Candido não teve como pretensão a formulação de uma teoria da literatura brasileira, dizia inclusive não ter vocação para abstração, que era muito pautado pelo senso do concreto. Ao fazer essa observação, nosso interesse é deixar claro que esses conceitos não devem ser tomados de modo abstrato ou estanque, pelo contrário, devem ser entendidos no âmbito do texto e do contexto em que foram produzidos.

Logo de partida, faz-se necessário dizer que o elemento central da crítica de Antonio Candido é a idéia de sistema literário, sistema esse cuja formação foi estudada profundamente no célebre Formação da Literatura Brasileira (2006a) e que, em linhas gerais (e por ora superficiais), pode ser entendido como o sistema que surge a partir da configuração efetiva de um público leitor, de um conjunto de autores reunidos sob interesses mais ou menos afins e, claro, a produção sistemática de obras literárias de maneira a constituir uma tradição. Aparentemente é uma noção simples, que poderia ser facilmente detectada em quaisquer pesquisas sobre o tema, no entanto, compondo a noção de sistema literário encontramos mediações fundamentais para sua configuração e que precisam ser estudadas com mais profundidade.

A primeira dessas mediações é justamente o conceito de formação, que pode ser entendida como a primeira e fundamental etapa da configuração do sistema literário. Para Candido, "trata-se então (...) de averiguar quando e como se definiu uma continuidade ininterrupta de obras e autores, cientes quase sempre de integrarem um processo de formação 
literária" (idem, p.26). Como veremos a seguir, ele aponta dois períodos marcantes da formação da literatura brasileira: o arcadismo e o romantismo. É no âmbito desses dois momentos que os elementos mínimos de produção, difusão e recepção das obras se constituirão.

$\mathrm{Na}$ base do processo de formação do sistema encontram-se as manifestações literárias, isto é, as obras que trataram do Brasil ou foram aqui produzidas num momento em que ainda não possuíamos uma vida literária propriamente dita e que

ainda não correspondiam a uma etapa plenamente configurada da literatura, pois os pontos de referência eram externos, estavam na Metrópole, onde os homens de letras faziam seus estudos superiores e de onde recebiam prontos os instrumentos de trabalho mental (CANDIDO, 2004, p. 22)

A importância das manifestações literárias diz respeito sobretudo ao desenvolvimento de um certo sentimento localista entre os colonos e também ao processo de transfiguração da realidade, responsável pelo "veio da exaltada celebração do país, que durante quase três séculos serviu de compensação para o atraso e o primitivismo reinantes"(idem, p.23). Desse período os maiores representantes são o pe. Antônio Vieira e Gregório de Matos.

No interior desse processo de formação, Candido aponta um duplo movimento:

De um lado, a visão da nova realidade que se oferecia e devia ser transformada em "temas", diferentes dos que nutriam a literatura da Metrópole. Do outro lado, a necessidade de usar a literatura de maneira por vezes diferentes "as formas", adaptando os gêneros às necessidades de expressão dos sentimentos e da realidade local. (opcit, p.14-15)

Essa última consideração do crítico configura a dialética local-universal, que vem a ser a relação entre a forma européia e a matéria local. Segundo Candido, a literatura chega ao Brasil como uma imposição, como parte do conjunto de ações das quais os colonizadores lançaram mão para se instalarem no Brasil e garantirem seu domínio político, cultural e econômico. Na 
literatura, a dialética local-universal se configura da seguinte maneira: a forma literária que chega aqui se encontra num estágio de grande refinamento técnico e erudito na Europa, pois é justamente a forma Classicista, que buscava retornar aos padrões da Grécia Antiga e Clássica. Nesse momento, encontramos a voga da rigidez das formas, principalmente por meio da normatização, que terá na figura de Boileau um de seus maiores representantes.

A compreensão desse momento é importante, porque possibilita verificar que, para ser bem aceito socialmente, o escritor tinha que buscar atender adequadamente as "normas formais universais". Por outro lado, o estudo da dialética entre forma e conteúdo nos ensina que a forma está sempre buscando ajustar-se adequadamente aos materiais (conteúdo), e no Brasil não foi diferente: a forma clássica importada quando chega às nossas terras encontra uma matéria que não se adequava a ela, principalmente no que se refere ao que se chamou de "cor local". Essa inadequação entre forma européia e materiais nativos terá várias consequiências interessantes por um lado e negativas por outro. Um dos benefícios da importação da forma clássica foi que a literatura produzida aqui pôde alcançar um bom nível em um período de tempo relativamente curto. Uma das desvantagens foi o fato de o estilo com ares eruditos e rebuscados se colocar como uma barreira a mais na difusão da literatura. Nesse sentido é também imprescindível lembrar que a literatura oficial não deu margem às contribuições indígenas e africanas, essas culturas foram sempre reprimidas pelos colonizadores.

Outro elemento indispensável para a compreensão do sistema literário brasileiro é o conceito de empenho da literatura na construção da nação. Segundo Candido, o projeto de construir uma literatura independente da de Portugal também foi o de construir uma nação. $O$ crítico explica que com "empenho" não quer dizer que a literatura "seja social ou deseje tomar partido ideologicamente"; na verdade, com esse conceito ele pretende apenas mostrar que a literatura

é toda voltada, no intuito dos escritores ou na opinião dos críticos, para a construção duma cultura válida no país. Quem escreve, contribui e se inscreve num processo histórico de elaboração nacional (CANDIDO, 2006a, p.20)

Nesse sentido, vale a pena observar dois episódios dentro dos momentos que o crítico chamou de decisivos para a formação da literatura brasileira. No primeiro deles, o Arcadismo, é 
interessante notar, por exemplo, como a tríade mineira - Cláudio Manoel da Costa, Tomás Antônio Gonzaga e Alvarenga Peixoto - esteve ligada à Inconfidência Mineira. No segundo momento, o Romantismo, encontraremos aquilo que Candido chamou de "Nacionalismo Literário", ou seja, a literatura, impulsionada pelos ideais da Revolução Francesa e pelo momento da Independência, vai desenvolver mais ainda os ideais nacionais. Esse empenho, esteticamente, será manifestado, por um lado, por meio do descritivismo exótico, do ufanismo e da caracterização estereotipada dos personagens; por outro lado, o empenho possibilitará a captação das fraturas da sociedade brasileira. A essa dialética de possibilidades configurada basicamente pelo caráter empenhado e pela dialética local-universal, Antonio Candido deu o nome de literatura de dois gumes (CANDIDO, 2006d).

Ainda no bojo dos conceitos básicos necessários para compreender a evolução sistema literário, cabe estudarmos a importância do que Candido chamou de consciências amena, catastrófica e dilacerada do atraso (CANDIDO, 2006c). Com esses conceitos o crítico pretende mostrar como a consciência do atraso em que o país se encontrava (e encontra) atuou no sistema literário, haja vista que a noção de "país novo" e posteriormente a noção de "subdesenvolvido" foram significativamente constitutivas na produção da literatura brasileira.

A idéia de país novo propiciou o surgimento de algumas atitudes fundamentais na nossa literatura e também na nossa intelectualidade, gerando principalmente o exotismo, a transfiguração do real, a elevação do esclarecimento a uma categoria de prestígio, os estereótipos do índio e do negro etc. Já a consciência do subdesenvolvimento desenvolveu-se de modo a levar os escritores e intelectuais a perceberem que as promessas de desenvolvimento e progresso eram um engodo e que os problemas do país não se resolveriam de modo tão fácil quanto se cria até então.

A consciência do subdesenvolvimento é apresentada como sendo composta por dois estágios distintos, a consciência catastrófica e a consciência dilacerada do atraso. A consciência catastrófica corresponde, na literatura, a um posicionamento estético diverso do que vinha se apresentando até então; nas palavras de Candido:

O que os caracteriza (...) é a superação do otimismo patriótico e a adoção de um tipo de pessimismo diferente do que ocorria na ficção naturalista. Enquanto este focalizava o homem pobre como elemento refratário ao progresso, eles 
desvendam a situação na sua complexidade, voltando-se contra as classes dominantes e vendo na degradação do homem uma conseqüência da espoliação econômica, não do seu destino individual (CANDIDO, 2006c).

Já a consciência dilacerada do atraso corresponde a um acirramento dessas tendências que já vêm anunciadas na consciência catastrófica. Neste momento, a nova consciência implica esteticamente na superação de certo naturalismo nativista fruto de "uma época onde triunfava a mentalidade burguesa e correspondia à consolidação das nossas literaturas" (ibidem). Ainda como explica o crítico:

Descartando o sentimentalismo e a retórica; nutrida de elementos não-realistas, como o absurdo, a magia das situações; ou de técnicas antinaturalistas, como o monólogo interior, a visão simultânea, o escorço, a elipse - ela implica não obstante em aproveitamento do que antes era a própria substância do nativismo, do exotismo e do documentário social. Isto levaria a propor a distinção de uma terceira fase, que se poderia (pensando em surrealismo, ou super-realismo) chamar de super-regionalista. Ela corresponde à consciência dilacerada do subdesenvolvimento e opera uma explosão do tipo de naturalismo que se baseia na referência a uma visão empírica do mundo (ibidem).

Com o estudo das implicações das consciências de subdesenvolvimento na história da nossa literatura, sobretudo no que se refere à constituição de uma vertente da literatura tão importante e produtiva como o regionalismo, pensamos ter concluído a apresentação dos conceitos básicos de Antonio Candido no que se refere à formação, consolidação e desenvolvimento do sistema literário. No entanto, gostaríamos ainda de chamar a atenção do leitor para mais dois conceitos do crítico, os de função social, ideológica e total (CANDIDO, 2006b) da literatura e o de dialética da ordem e da desordem (CANDIDO, 1993).

Quando fala de função social, ideológica e total da literatura, Candido tem em mente perceber o funcionamento da literatura na vida social. Segundo o autor: 


\begin{abstract}
A função total deriva da elaboração de um sistema simbólico, que transmite certa visão do mundo por meio de instrumentos expressivos adequados. Ela exprime representações individuais e sociais que transcendem a situação imediata, inscrevendo-se no patrimônio do grupo. (...) A função social comporta o papel que a obra desempenha no estabelecimento de relações sociais, na satisfação de necessidades espirituais e materiais, na manutenção ou mudança de uma certa ordem na sociedade;" e o "lado voluntário da criação e da recepção da obra concorre para uma função específica, menos importante que as outras duas e frequentemente englobada nelas, e que se poderia chamar de função ideológica, - tomando o termo no sentido amplo de um desígnio consciente, que pode ser formulado como idéia, mas que muitas vezes é uma ilusão do autor, desmentida pela estrutura objetiva do que escreveu. (CANDIDO, 2006b, p.5556 , grifo meu)
\end{abstract}

Esses conceitos, apesar de serem desenvolvidos apenas no ensaio "Estímulos da Criação Literária", podem ser identificados ao longo de outros estudos, tais como "A literatura e a vida social" e "O direito à literatura", e também devem ser entendidos como formulações dialéticas. Com eles o crítico pretende mostrar "qual a influência exercida pelo meio social sobre a obra de arte" e "qual a influência exercida pela obra de arte sobre o meio" (CANDIDO, 2006b, p.31), sendo que uma das principais conclusões que se extrai dessa investigação é justamente que "não convém separar a repercussão da obra da sua feitura, pois sociologicamente ao menos, ela só está acabada no momento em que repercute e atua" (CANDIDO, 2006b, p.28).

Com isso chegamos ao último dos conceitos a ser trabalhado neste ensaio, que é o de dialética da ordem e da desordem. Este conceito é desenvolvido no célebre ensaio "Dialética da Malandragem", no qual Candido, ao estudar o romance Memórias de um Sargento de Milícias, de Manoel Antônio de Almeida, percebe que ali está configurada na figura do malandro, no caso o personagem Leonardo Pataca, uma estrutura denominada sociedade do favor. Esse tipo de estrutura social é fruto de uma organização maior em que de um lado encontram-se os detentores do capital, que no Brasil correspondem aos latifundiários, senhores de engenho etc., e de outro lado encontram-se os trabalhadores produtivos explorados, naquele momento os escravos negros. Acontece que entre uma "classe" e outra existe um grupo que nem detém o capital, nem é propriamente o trabalhador produtivo: são os chamados homens livres, grupo constituído pelos agregados, pequenos comerciantes, pequenos funcionários públicos etc. Não tendo ocupação certa ou segura, essa camada da população vai viver do favor, ou seja, de prestar pequenos 
serviços escusos, de bajular os grandes a fim de ganhar recompensas e de ludibriar os pequenos a fim de levar vantagem. Desse modo Candido nos mostra de que maneira Manoel Antonio de Almeida consegue captar e plasmar literariamente essa estrutura social e, consequentemente, as estruturas maiores em que esta se insere.

3

Após esse breve panorama de alguns conceitos da crítica de Antonio Candido, esperamos ter ficado claro o modo como ele trabalhou aspectos fundamentais da história da literatura brasileira, constituindo não só o ponto mais alto de nossa crítica literária, mas também entrando para o rol dos intérpretes do Brasil.

Com nossa análise, buscamos mostrar que o conjunto de conceitos presentes na obra de Candido constitui ele próprio um sistema, que podemos chamar de "sistema conceitual crítico", e que vem se mostrando um poderoso e fecundo instrumento de compreensão da literatura brasileira e do Brasil.

Por meio dos estudos literários empreendidos por mais de quarenta anos, Candido leva a cabo um projeto que tem fortes vínculos com aquilo que ele próprio identificou em nossa literatura como empenho. Tendo sido profundamente engajado nos assuntos de seu país, tendo passado pela ditadura do Estado Novo e posteriormente pela ditadura militar, Candido fez de seus escritos uma poderosa ferramenta de compreensão do Brasil. Ao mostrar como a literatura e a sociedade brasileira se formaram, o crítico nos possibilita entender os passos que demos enquanto país até chegarmos no estágio (calamitoso, por sinal) em que estamos e nos coloca a obrigação de continuarmos sua empreitada (e de tantos outros que se empenharam nesse projeto) na busca por compreender o país e na luta por possibilidades de transformação social radical.

\section{REFERÊNCIAS BIBLIOGRÁFICAS}

ANDRADE, Carlos Drummond de. "Esboço de Figura". In: Esboço de Figura: homenagem a Antonio Candido. São Paulo: Livraria Duas Cidades, 1979. Também disponível em http://acd.ufrj.br/pacc/literaria/esboco.html

ARANTES, PAULO. "Providências de um crítico literário na periferia do capitalismo". In: Sentido da Formação. Rio de Janeiro: Paz e Terra, 1997.

. Sentimento da Dialética na Experiência Intelectual Brasileira: Dialética e 
dualidade segundo Antonio Candido e Roberto Schwarz. Rio de Janeiro: Paz e Terra, 1992.

BASTOS, Hermenegildo. "Antonio Candido: Palavras-Chave". Texto Inédito.

CANDIDO, Antonio. Formação da Literatura Brasileira: Momentos Decisivos 1750-1880. 10ed. Rio de Janeiro: Ouro Sobre Azul, 2006a.

"Estímulos da Criação Literária"e "A literatura e a vida social". In: Literatura e Sociedade. 9 ed. Rio de Janeiro: Ouro Sobre Azul, $2006 \mathrm{~b}$.

"Literatura e Subdesenvolvimento". A Educação Pela Noite. Rio de Janeiro: Ouro Sobre Azul, 2006c.

Sobre Azul, 2006d.

"Literatura de dois gumes". A Educação Pela Noite. Rio de Janeiro: Ouro

Iniciação à Literatura Brasileira. 4 ed. Rio de Janeiro: Ouro Sobre Azul, 2004.

Cidades, 1993.

"Dialética da Malandragem". In: O Discurso e a Cidade. São Paulo: Duas

JACKSON, Luís Carlos. A Tradição esquecida: Os Parceiros do rio bonito e a sociologia de Antonio Candido. Minas Gerais: Ed. UFMG, 2002.

SCARABÔTOLO, E. F.; D'INCAO, M.A. Dentro do texto, dentro da vida: ensaios sobre Antonio Candido. São Paulo: Companhia das Letras: Instituto Moreira Salles, 1992.

SCHWARZ, Roberto. "Originalidade da Crítica de Antonio Candido". In: Revista Novos Estudos CEBRAP, n’ 32, São Paulo,1992.

TAVARES, Carlos. "O crítico dos contrários". Entrevista concedida por Antonio Candido ao Caderno Pensar do Correio Braziliense em 03 de maio de 2007. 